\title{
A casa na parcela: a construção do lugar da família nos assentamentos da Zona da Mata de Pernambuco
}

\author{
The house on the plot: making place for the family within the settlements of \\ Zona da Mata de Pernambuco
}

La casa en la parcela: la construcción del lugar de la familia en los asentamientos de la Zona da Mata de Pernambuco

Ana Luísa Micaelo*

\section{Resumo}

O modelo de reforma agrária colocado em prática no Brasil nas últimas três décadas presume uma espécie de quadro atemporal, baseando-se numa unidade operativa de família nuclear que não comporta a noção de prolongamento temporal e reprodução intergeracional. Apesar de a reprodução familiar ser uma das preocupações mais características das comunidades camponesas, a sucessão não foi prevista neste processo. De forma a compreendermos como os assentados lidaram com essa situação, este artigo apresenta uma análise etnográfica das casas num assentamento rural da Zona da Mata de Pernambuco onde ocorreu um debate intenso entre diferentes modelos de organização espacial. Partindo então da observação da diversidade de categorias e materiais das casas, propõe-se uma interpretação do seu significado ligado à historicidade das dinâmicas familiares e aos sentidos locais de posse da terra.

Palavras-chave: Família. Reforma agrária. Zona da Mata de Pernambuco.

\footnotetext{
Doutora em Antropologia pelo Instituto de Ciências Sociais da Universidade de Lisboa. Pesquisadora do Instituto Universitário de Lisboa (ISCTE-IUL), Centro em Rede de Investigação em Antropologia (CRIA), Lisboa, Portugal, Linha(s) pesquisa: Governação, Políticas e Quotidianos. E-mail: ana.micaelo@iscte.pt
}

Recebido em 115/03/2017 - Aprovado em 20/05/2017 http://dx.doi.org/10.5335/hdtv.17n.2.7491 


\section{Introducão}

O modelo de reforma agrária colocado em prática no Brasil nas últimas três décadas presumiu uma espécie de quadro atemporal. Segundo este modelo, cada parcela de terra é atribuída a uma família que a deverá devolver ao Instituto Nacional de Colonização e Reforma Agrária (Incra) no caso de abandonar o assentamento ou após a morte dos seus titulares. A sucessão não estava, portanto, prevista neste processo. Apesar de a reprodução familiar ser uma das preocupações mais características das comunidades camponesas, ela não tem sido tratada analiticamente em relação aos programas de reorganização do mundo rural espelhados nos movimentos de reforma agrária na América Latina e, em particular, no Brasil.

Neste artigo apresento o resultado de uma pesquisa antropológica realizada entre 2009 e 2014 num assentamento de reforma agrária da Zona da Mata de Pernambuco onde desenvolvi a análise destas problemáticas (MICAELO, 2016). ${ }^{1}$ Trata-se de um assentamento que foi constituído a partir da desapropriação de um engenho de cana-de-açúcar de cerca de 1200 hectares situado na região de Vitória de Santo Antão, na transição geográfica e climatérica entre as regiões da Mata Atlântica e do Agreste pernambucano. Depois de uma série de três ocupações de terra, pedidos de vistoria, processos de fiscalização e judiciais levados a cabo pelo Movimento dos Trabalhadores Rurais Sem Terra (MST) durante a década de 1990, o assentamento Arupema foi formalmente criado pelo Incra em 1998. ${ }^{2}$ Num local onde viviam 19 famílias de trabalhadores do engenho, os moradores de engenho, passaram a viver oficialmente 90 famílias assentadas, tendo sido atribuída uma parcela de terra equivalente a cada uma delas e onde cada família pode plantar livremente a cultura que quiser. Ao contrário de uma plantação repleta de cana ou de um engenho mais ou menos abandonado, o assentamento passou a ser um espaço habitado. À data do início da pesquisa, Arupema era um dos assentamentos mais consolidados da Zona da Mata, existindo há tempo suficiente para que a questão da habitação de gerações descendentes dos primeiros assentados já se colocasse de forma clara.

Assim, depois de uma fase de conhecimento extensivo de dezenas de assentamentos da região, o assentamento Arupema foi escolhido para realizar de trabalho de campo com observação participante, desenvolvendo uma abordagem etnográfica sensível às dinâmicas da vida quotidiana e aprofundando a questão da dinâmica temporal implicada na sucessão geracional. Contando com mais de uma década após a sua constituição oficial, no assentamento Arupema a geração das pessoas a quem foi atribuída uma parcela de terra, ou seja, os assentados, tinha já filhos adultos quando, em 2010, ali iniciei o trabalho de campo. Neste artigo proponho a análise etnográfica das dinâmicas de construção das casas das famílias assentadas como uma das formas de compreendermos como os filhos dos assentados lidam com essa situação.

Tal como noutros contextos rurais da América Latina e do Sul da Europa, também aqui o termo casa se refere tanto à construção material quanto às pessoas que nela habitam, tornando-se numa característica central 
da organização social e veículo de análise para o estudo do parentesco (FREYRE, 2001; PINA-CABRAL, 1991; CARSTEN, 2004; VIEGAS, 2007). Partindo então da observação da diversidade de categorias e materiais das casas, propõe-se uma interpretação do seu significado ligado à historicidade das dinâmicas familiares e aos sentidos locais de posse da terra.

Por sua vez, a forma como ocorreu o debate entre dois modelos diferentes de organização espacial do assentamento aponta para a necessidade de uma problematização da territorialidade, atendendo especificamente ao modo como as famílias concebem a sua relação com a terra. Em Arupema, o momento da criação do assentamento despoletou atitudes diferenciadas face à continuidade do local de habitação e à sucessão geracional por parte dos dois grupos que viriam a constituir a população assentada: (a) os antigos moradores do engenho Arupema, que puderam permanecer depois de constituído o assentamento e a quem foi atribuída uma parcela de terra; e (b) aqueles que, tendo acampado com o MST no engenho reivindicando a sua desapropriação, foram também selecionados pelo Incra enquanto beneficiários da reforma agrária. Apesar dos diferentes modos de acesso à terra, em ambos os casos se constata uma valorização da permanência da família e dos seus sucessores no mesmo espaço de morada.

\section{A casa na parcela}

Uma das particularidades de Arupema no panorama da região é o fato de se tratar de um assentamento criado a partir da ação do MST, mas que depois "passou para a Fetape", a Federação dos Trabalhadores na Agricultura do Estado de Pernambuco. Esta estrutura que agrega os sindicatos dos trabalhadores rurais de todo o estado tornou-se também num movimento de luta pela reforma agrária e goza de grande força política por toda a Zona da Mata devido à grande implementação dos sindicatos entre os trabalhadores da cana-de-açúcar (SIGAUD; ROSA; MACEDO, 2008). Sendo pouco comum que um assentamento mude de movimento que o apoia, esta situação torna-se interessante justamente pelo que manifesta. Ora, esta passagem do MST para o sindicato deveu-se a uma dissidência que aconteceu num momento inicial, quando se discutia, entre outros assuntos, o modelo de organização espacial a ser implementado no assentamento e, especificamente, onde se deveriam construir as casas dos assentados.

A proposta do MST assentava na divisão clara entre o espaço produtivo, que corresponde às parcelas, e o espaço residencial, concentrado numa agrovila. Trata-se de uma organização territorial, mas também social e política do assentamento, em que as casas de habitação são construídas em arruamentos numa área comunitária, juntamente com os demais equipamentos e infraestruturas de uso coletivo, como a sede da associação, a escola, etc. De acordo com este modelo implementado em vários outros assentamentos organizados pelo MST por todo o país, a restante área do assentamento deve ser dividida em parcelas semelhantes entre 
si que são atribuídas a cada família e cuja função deve ser exclusivamente a da exploração agrícola.

Como acontece comummente nos assentamentos do MST que se estabeleceram nos antigos engenhos da Zona da Mata de Pernambuco, também em Arupema a área comunitária foi criada no espaço que correspondia à anterior sede do engenho. Esse espaço tem algumas características facilitadoras do acesso comum a recursos materiais, tais como a eletrificação e os arruamentos para o exterior. $\mathrm{Na}$ sede do antigo engenho Arupema, além da casa-grande, do barracão e da cocheira, existiam ainda algumas casas de trabalhadores que se encontravam dispostas em arruado e que, ao contrário das casas dos restantes moradores, situadas fora da sede, não tinham qualquer área de plantação associada. Note-se que as casas de morada situadas fora do engenho eram bastante valorizadas neste universo social da plantation (PALMEIRA, 2009). Estes trabalhadores eram então conhecidos como moradores com sítio, uma vez que as suas casas estavam ligadas a um espaço de cultivo relativamente autónomo e que podia incluir árvores de fruto, assemelhando-se à matriz cultural camponesa nordestina do sitio (WOORTMANN, 1995).

Assinalam-se dois momentos chave nesta transição do engenho para o assentamento que nos permitem aferir a forma como a terra é concebida ao longo do processo de reforma agrária neste contexto. O primeiro momento é aquele em que a terra foi cortada. Corresponde à fase em que a propriedade é dividida em lo- tes semelhantes - tidos na legislação como «unidades agrícolas familiares» - que serão atribuídos a cada uma das famílias previamente cadastradas para ocuparem o assentamento. De acordo com os procedimentos do Incra, a condição do morador, que implica a ocorrência de "culturas permanentes", foi tida em consideração na organização do assentamento Arupema. Para o efeito, os moradores com sítio foram consultados no processo de identificação das áreas ocupadas e puderam escolher se mantinham a mesma localização das suas moradas, o que aconteceu em todos os casos. Deste modo, aquela que viria a ser a área da sua parcela foi delimitada ao redor da casa que já habitavam, respeitando também a área de plantação que detinham antes. Assim, as medições da propriedade demarcaram as noventa parcelas de maneira a incorporar a casa de morada, cultivos e árvores destes antigos ocupantes.

A permanência dos moradores nas casas onde moravam e nas terras onde tinham os seus sítios evidenciou o reconhecimento e valorização do sítio por parte de todos os envolvidos: antes de mais, pelos próprios moradores e proprietários, que permitiam a sua existência e não contestaram o seu registo aquando do processo de desapropriação; numa segunda fase, pelo Incra, que reconheceu a localização das culturas permanentes dos moradores na delimitação das parcelas; e por fim, pelos outros assentados que chegaram a Arupema através do acampamento do MST e que não contestaram essas salvaguardas na terra conquistada, acabando também 
eles por vir a localizar suas casas nas respetivas parcelas. Este processo demonstra que o sítio corresponde de fato a um modelo camponês partilhado intersubjetivamente neste contexto e que podemos considerar, tal como outros estudos têm vindo a defender (WANDERLEY, 2003), ser o ideal de territorialidade que os assentados buscam quando se envolvem no processo de reforma agrária:

Esses pé de pau aqui foi tudinho eu que plantei. Plantei um de cajá lá em cima no rumo do irmão Biu. Graviola, laranja, jaca, tudo fui eu que plantei. Até um pé de sapota. Todo o ano eu arrumo um trocado bom de abacate. [...] Eu tinha muita vontade de morar num lugar para fazer uma fruteira bem linda ao redor da minha casa. E eu tenho! ${ }^{3}$

No caso dos moradores de arruado, respeitando também a sua preferência, a parcela atribuída pelo Incra foi delimitada na proximidade da antiga sede do engenho, onde se situavam as suas casas. Assim, a delimitação da parcela correspondeu para eles à possibilidade de ter um espaço de habitação e cultivo aproximado ao do sítio e, mesmo assim, em continuidade com o local onde moravam no período do engenho.

Além destes ocupantes prévios, que tiveram prioridade no cadastramento realizado pelo Incra, o assentamento foi ainda povoado com as famílias que chegaram a Arupema por via da ocupação do MST e que são ocasionalmente apelidadas de sem-terra ou acampados pelos demais. Também elas referem ter participado no processo de escolha do lugar de residência e trabalho por ocasião da demarcação de parcelas. Como a demar- cação das parcelas foi um processo demorado, uma grande parte dos assentados que haviam acampado residia em casas improvisadas na sede do engenho. Por serem abrigos pequenos e insalubres, estes barracos não eram consideradas propícios à habitação de crianças. Só quando as parcelas foram definitivamente demarcadas é que os acampados puderam então começar a construir as suas casas de raiz, o que permitiu, pela primeira vez depois do acampamento, a reunião da família.

Muitos sem-terra tinham também encontrado locais onde começaram a cultivar hortas e roçados para consumo próprio durante o acampamento e, inclusivamente, plantado árvores de fruto, acreditando que não teriam mais de mudar de lugar. No entanto, devido a um erro técnico ocorrido no loteamento que levou a que as parcelas demarcadas no final ficassem mais pequenas do que as restantes, a medição da terra teve de ser repetida. Tratava-se de um momento marcante na instauração de uma ordem social em que justamente a uniformização era tida como um ato político. A sua resolução implicou a sobreposição de algumas parcelas demarcadas anteriormente e onde outros assentados haviam já começado a plantar, o que gerou conflitos. Na impossibilidade de todos os assentados escolherem consensualmente as suas parcelas, a opção do Incra constou em atribuir aleatoriamente os lotes restantes.

Um segundo momento aquando da fundação do assentamento deu azo a uma contenda quanto à localização das casas de habitação dos assentados, debatendo-se os modelos de assentamento com localização 
das casas nas respetivas parcelas ou na agrovila. A apologia da agrovila prende-se com a possibilidade de a construção das casas não ficar dependente do loteamento da terra, que, por requerer trabalho técnico externo, pode ser demorado. Na concepção do MST, a agrovila é um modelo de organização social e político que promove a coletivização do espaço, reservando para as parcelas a área destinada ao cultivo e não necessariamente à habitação dos assentados. E este é um dos pontos nevrálgicos da implementação da reforma agrária na região, que nos remete para a disputa entre os referenciais ideológicos e metodológicos diferenciados do MST e dos sindicatos rurais tão influentes na região.

No entanto, em Arupema, a maior parte dos titulares das parcelas - fossem eles antigos moradores do engenho ou os assentados que haviam acampado inicialmente com o MST - preferiu construir as suas casas nas respetivas parcelas. Esta decisão, defendida pelo anterior administrador do engenho que havia permanecido no assentamento e que mais tarde viria a presidir à associação do assentamento e ao Sindicato dos Trabalhadores Rurais local, correspondia à vontade da maior parte dos assentados. Mas entrava em conflito direto com o modelo que o MST propunha e que tinha vindo a implementar no Sul do país e no sertão pernambucano antes de retornar à Zona da Mata. Este acontecimento foi de tal forma importante que acabou por ser um dos fatores que contribuíram para a diminuição da influência do MST em Arupema.

Uma vez que os moradores com sítio preferiram manter as suas antigas casas de morada, a questão colocava-se sobretudo aos moradores de arruado e aos novos ocupantes, os sem-terra. Ainda que as situações de partida que os moradores e os acampados dispunham implicassem necessariamente diferentes soluções, assim aconteceu também entre muitos dos assentados que faziam parte do movimento. Segundo Zé Celestino, que havia acampado com o MST lutando pela terra, construir a casa na parcela tem vantagens: "Lá tem casa, tem onde comer, onde deixar as roupas, tudo perto de onde trabalha". ${ }^{4}$ A proximidade com o local de trabalho e o maior controlo sobre o que acontece na sua parcela foram argumentos generalizados a favor da localização da casa na parcela.

É melhor morar no sítio. Em arruado os vizinhos vêem tudo, já fica olhando... No sítio ninguém olha a vida de ninguém. É muito bom, tem as árvores, o sombrio... A ventilação é outra. Aqui, se eu me deitar, não tem quem diga: 'O Seu Vítor não tá trabalhando hoje, porquê?...' No arruado 'Aquele cabra não quer trabalhar mais hoje, só quer viver em casa é? Aquela mulher só é dentro de casa, é, não faz mais nada, é?'.5

Entre os moradores com sítio e os que viviam no arruado as soluções possíveis eram, contudo, diferentes. Os primeiros preferiram continuar a morar na casa que ocupavam já no espaço do engenho, donde não chegaram sequer a sair durante o período de transição para assentamento. Esta manutenção das casas apenas foi possível para os moradores com sítio. Uma vez que as casas que existiam previamente no arruado eram feitas de taipa (e barro) e haviam sido destruídas com a instauração do assentamento, os moradores que viviam no arruado tive- 
ram de construir uma nova casa, usando para isso o financiamento disponibilizado pelo Incra para comprar materiais de construção e realizar a empreitada. Também no caso dos acampados houve a necessidade de construir uma nova casa para habitar, uma vez que não existiam no local casas suficientes para todas as noventa famílias a quem foi atribuído um lote.

Ainda assim, com a constituição do assentamento construiu-se um novo arruado, onde um pequeno número de famílias decidiu fazer a casa. Em conformidade com os princípios do MST, essas pessoas argumentavam que a parcela se localizava muito longe da agrovila, preferindo assim estar mais próximos do centro e apenas se deslocando para a terra com o objetivo de a trabalhar. No entanto, com o decorrer do tempo, o número de famílias a residir na agrovila foi diminuindo, restando apenas três casas de arruado ocupadas à data da realização do trabalho de campo. Esta preferência dos assentados em morar nas casas na parcela, ainda que mais precárias do que as da agrovila, foi verificada por toda a Zona da Mata nordestina (LEITE et al., 2004).

Segundo Wendy Wolford, que estudou o MST em várias regiões do Brasil, este movimento não foi bem-sucedido na manutenção da sua forte influência na região açucareira devido ao fato de os "imaginários espaciais" dos moradores estarem moldados pelas hierarquias sociais e estratégias de reprodução extremamente segmentárias que caracterizavam a vida nos engenhos (WOLFORD, 2004). A questão ganha relevância devido ao princípio de assentar os moradores do engenho desapropriado pri- meiro e só depois aqueles que lutaram pela sua desapropriação com o movimento. Do ponto de vista do MST, isto é problemático na medida em que os moradores, não estando organizados, não gozam da mesma legitimidade sobre a terra que foi conquistada pela luta dos sem-terra. Por outro lado, os moradores de engenho são menos propícios a cumprir o seu ideal da reforma agrária que faz corresponder a uma família uma parcela, começando a "criar condomínio», ou seja, a apropriar-se da parcela como espaço de residência da família, construindo várias casas, em vez de privilegiarem a produção.

Há, portanto, duas dimensões a considerar: uma de operacionalidade e outra ideológica. O lema "a terra para quem a trabalha", que fundamenta o modelo de reforma agrária do MST posiciona-se perentoriamente contra a ideia da propriedade privada da terra. Uma vez que não se considera ter havido mudanças económicas e políticas estruturais na região que protejam os pequenos proprietários do predomínio do latifúndio e da monocultura da cana, a emancipação dos assentamentos, sob forma de uma transformação da concessão de uso das parcelas em propriedade privada - o que permitiria aos assentados decidirem que uso dar à terra, inclusivamente, dividindo-a ou vendendo-a - não foi uma bandeira da luta do movimento.

Do ponto de vista dos edifícios propriamente ditos, desde o início do assentamento que ficou visível uma certa distinção social dos moradores com sítio em relação tanto aos moradores do arruado quanto aos assentados que haviam chegado por via do acampamento do MST. Esta distinção social 
que perdura em Arupema espelha-se materialmente nas características arquitetónicas, antiguidade, aparência e nos materiais utilizados na construção das várias casas dos assentados. Assim, identificam-se três tipos de casas edificadas atualmente no assentamento Arupema: (a) as antigas casas de morada, construídas no tempo do engenho com um tipo de tijolo maciço ou pedra; $(b)$ as casas de tijolo comum, construídas no início do assentamento, já depois do ano 2000; e (c) as mais recentes casas de taipa, que se vão erguendo ao redor, nos terreiros das parcelas das famílias.

Figura 1 - Casa de um antigo morador de engenho no assentamento Arupema (novembro de 2010)

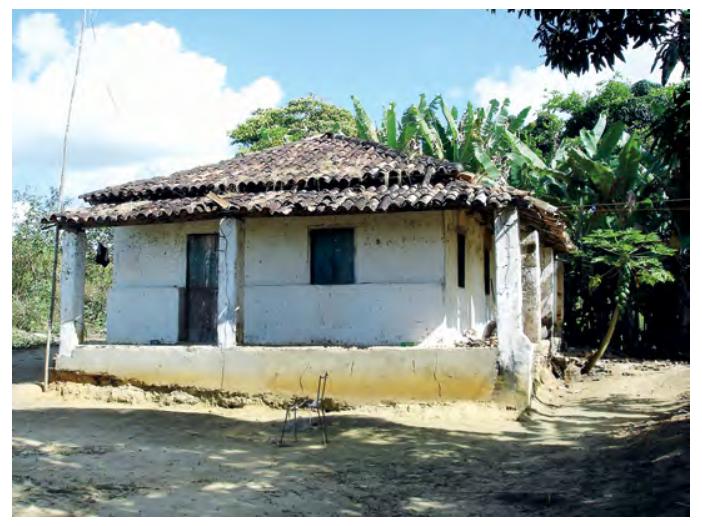

Fonte: arquivo da autora.

Estas antigas casas de morada dos trabalhadores do engenho foram construídas com um tipo de tijolo manual e maciço que se distingue claramente daqueles usados posteriormente nas construções de alvenaria. Em alguns casos, quando se tratava de casas de moradores com funções prestigiadas no engenho, os edifícios tinham fun- dações e alpendres de pedra, como no caso ilustrado pela Figura 1, onde se exibe a casa do antigo cabo de Arupema, que permanecia habitada à data do trabalho de campo. Apesar das condições difíceis que ali viviam no momento em que ocorreu o processo de desapropriação, estes moradores são aqueles que permaneceram durante mais tempo em Arupema e habitaram ininterruptamente as respetivas casas até aos dias de hoje. Este aspecto demonstra o forte investimento na casa de morada, assim como na sua preservação.

Por sua vez, àqueles moradores que não habitavam casas de pedra, mas de taipa, cabia a condição menos prestigiada na hierarquia do engenho. Recorde-se que, tal como acontecia entre os foreiros da Zona da Mata algumas décadas antes, tanto as casas de morada de taipa como as outras, pertenciam aos proprietários da terra (HEREDIA, 1979). Se é verdade que os moradores com sítio puderam permanecer na casa que já habitavam, todos os outros assentados de Arupema - acampados, moradores de arruado e moradores que viviam em casa de taipa - construíram uma nova casa. Usando um crédito para a habitação disponibilizado pelo Incra, essas novas construções foram feitas de tijolo. Mas um tipo de tijolo distinto daquele usado nas antigas casas do engenho. Na verdade, tanto o desenho da casa e a organização interna do seu espaço, como o tipo de materiais utilizados foram estabelecidos e sujeitos a aprovação por parte do Incra, que promovia a adoção deste modelo de casa de alvenaria. 
Figura 2 - Casa de tijolo de uma família assentada (assentamento Arupema, dezembro de 2010)

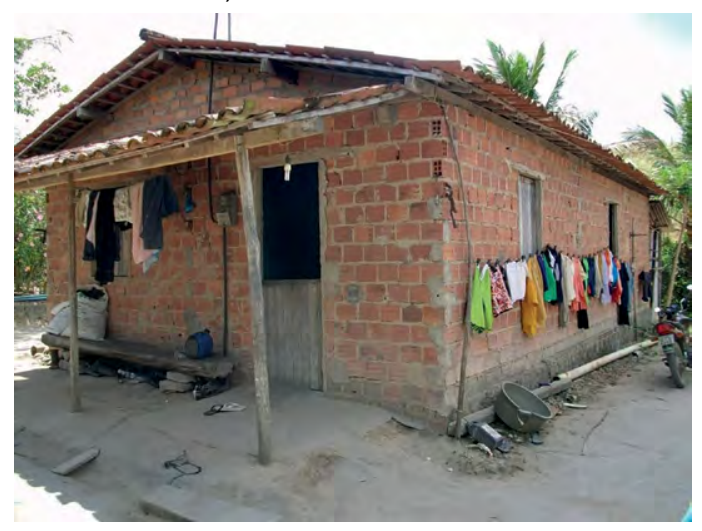

Fonte: arquivo da autora.

Na Figura 2 é possível ver uma dessas casas de tijolo construídas em Arupema a partir dos anos 2000, chamadas localmente de alvenaria/padrão. Elas mantêm genericamente a arquitetura típica da casa regional rural, com duas janelas laterais e uma porta frontal para o terreiro e outra para as traseiras.

\section{Asucessão da casa}

Como referi no início, quando se coloca a questão da sucessão da parcela, dado o quadro atemporal do sistema da reforma agrária, que concebe a parcela como uma unidade de terra concedida provisoriamente para ser trabalhada por uma família composta pelo casal assentado (titular) e seus descendentes, os pais não podem passar a parcela para o nome dos filhos. O sistema baseia-se numa unidade operativa de "família nuclear", sincopada, ou seja, não comportando uma noção de prolongamento temporal e reprodução intergeracional (PINA-CABRAL, 1991, p. 139).
Nesta concepção da reforma agrária não foi prevista a sucessão geracional da terra, uma vez que os titulares da parcela não podem passá-la para os filhos, nem em vida, nem no caso de morte:

Especificamente sobre as práticas de herança após a morte do titular da terra, a legislação agrária impede o fracionamento do lote de acordo com limites impostos pelo Estado. Desta forma, o Estado constrói uma representação à qual a família de assentados deve corresponder, sob pena de lhes ser retirada a posse da terra (CORDEIRO, 2010, p. 104).

Como a herança é um regime legal que não se aplica aos beneficiários da reforma agrária, no caso de morte do casal a quem foi concedida a parcela não existem preceitos administrativos que dêem conta da situação, deixando que cada caso particular venha a ser resolvido com base num acordo da associação do respectivo assentamento. Esta deverá encaminhar o assunto para o Incra pela via administrativa e, deste modo, proceder-se-á a uma nova inscrição na relação dos beneficiários da reforma agrária, para assim atribuir um novo título de concessão de posse.

Um dos poucos trabalhos que têm analisado a questão da sucessão na família em assentamentos de reforma agrária foi realizado num contexto onde o título definitivo de propriedade já havia sido atribuído às famílias assentadas. Neste caso, a problematização prende-se, portanto, com a articulação entre os arranjos familiares locais e a lei geral sobre o direito sucessório (CORDEIRO, 2010, 2011). Esta situação de assentamentos emancipados não era, à data da realização do trabalho, prática 
comum no panorama nacional e em Pernambuco continuava a ser especialmente rara. Com efeito, a limitada aplicação do procedimento de emancipação nos assentamentos rurais em Pernambuco relaciona-se com duas ordens de argumentos.

Por um lado, e reconhecendo que a ação dos movimentos de luta pela terra tem sido determinante na realização efetiva da reforma agrária no Brasil por parte do Estado (SIGAUD; ROSA; MACEDO, 2008), há que ter em conta que o título de propriedade da terra e, logo, a possibilidade de venda das parcelas não constam da pauta de ação política dos movimentos justamente por se considerar que as terras destinadas à reforma agrária devem ser protegidas das sucessivas pressões do mercado. Além do mais, esta situação poderia ser vantajosa para os assentados, uma vez que compete ao Incra, o órgão que tem a tutela dos assentamentos, a elaboração de políticas públicas dirigidas às necessidades específicas destas populações.

Por outro lado, o regime de herança não é compatível com o modelo social de reforma agrária que sustenta a concepção do MST. De acordo com o lema: "a família assentada tem que estar em luta", os filhos dos assentados devem procurar uma parcela para si num acampamento que venha a dar origem a um novo assentamento. Segundo Jaime Amorim, um dos principais dirigentes do MST em Pernambuco e que entrevistei em Maio de 2011, a substituição das gerações é uma preocupação permanente do movimento. Daí que o
MST tenha apostado na formação da juventude para que permaneça na atividade agrícola. A sua proposta assenta na alteração do modelo de desenvolvimento, vendo na agricultura familiar a alternativa à apropriação privada da terra e ao regime de monoculturas. Esta posição reflete-se assim na irresolução da questão da emancipação, ainda que transcorridos os previstos dez anos da fundação do assentamento, como é o caso em análise.

Todavia, a nova geração dos filhos dos titulares vai crescendo e, portanto, as soluções de vida vão sendo encontradas na prática, mesmo que à revelia de alguns procedimentos burocráticos. Veremos então as soluções que têm vindo a ser encontradas em Arupema face às restrições resultantes deste hiato. Ao contrário da geração dos titulares da parcela, os jovens filhos dos assentados não dispunham de recursos para construir a casa nem de uma área de terreno para a nova família que viessem a constituir. A observação dos casos que conheci em Arupema mostra que eles recorriam aos materiais de construção disponíveis localmente, tais como barro, madeira e folhas retiradas da mata e constroem a casa na parcela do pai do noivo, tendência que respeita o princípio da virilocalidade, segundo um modelo varonil. À medida que o tempo passava e os seus donos iam tendo condições, estas casas de taipa foram sendo melhoradas, por exemplo, através da colocação de telhas de barro, reboco e pintura das paredes. 
Figura 3 - Casa de taipa de um filho de assentados no terreiro dos seus pais (assentamento Arupema, novembro de 2010)

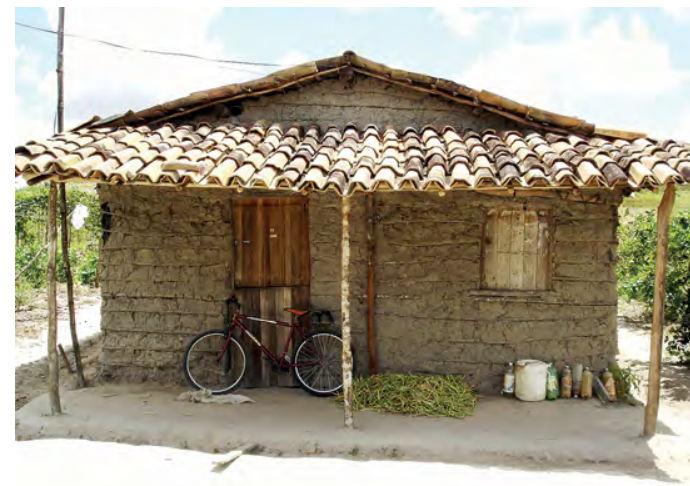

Fonte: arquivo da autora.

O aparecimento destas casas dos filhos dos titulares ao redor das casas dos pais prende-se, evidentemente, com o ciclo de vida familiar. Antecipando o casamento, é esperado que o filho mais velho constitua a sua casa na proximidade da dos pais. Ao contrário das outras pessoas que, não tendo qualquer ligação familiar com os assentados, possam residir no espaço do assentamento e que são, por essa razão, vistas com um certo grau de ilicitude, é consensualmente aceite que a geração dos filhos dos assentados seja integrada desta forma nas parcelas dos pais. Esta geração não tem título de posse da terra, não é representada na associação do assentamento e não tem acesso a créditos enquanto agricultores familiares, por dificuldade em provar que vivem de fato do trabalho da terra. A inexistência destes reconhecimentos formais estabelece hierarquias e cria restrições diretas à sua sustentabilidade exclusiva com o trabalho na parcela. Aliás, uma boa parte destes filhos de assentados recorre também ao trabalho assalariado fora do assentamento, de maneira a completar o seu rendimento familiar. Mesmo assim, no conjunto do assentamento, eles têm um estatuto reconhecido como os sucessores dos titulares. Este sistema varonil que se vai implementando, parece protegê-los.

Entre as famílias de antigos moradores que ficaram a residir na antiga casa de morada, esta gestão da casa das várias gerações foi feita de outra forma. Dado que puderam preservar a casa onde habitavam, alguns destes antigos moradores cederam-na a um dos filhos e usaram o crédito inicial para construir uma outra casa, de tijolo, para onde se mudaram. Esta casa passou a ser a casa "oficial" da parcela, evitando assim criar problemas de ordem formal. Desta feita, possibilitam que um dos seus filhos permanecesse na antiga casa de morada.

As soluções para a sucessão podem variar e, da mesma forma que os antigos moradores procuraram estabelecer uma certa continuidade familiar, cedendo a casa de morada ao filho mais velho, podemos dizer que a casa de taipa construída pelos filhos dos outros assentados, que chegaram como sem-terra, marca também uma continuidade com a trajetória dos próprios pais, cuja história de vida está muito marcada pela passagem por vários acampamentos onde construíram as suas barracas de taipa e lona preta. Em Arupema, como em tantos assentamentos que já foram objeto de estudos antropológicos, esta vivência da luta pela terra é central do ponto de vista da forma como constroem a sua identidade social enquanto assentados da reforma agrária (SIGAUD, 2000; WANDERLEY, 2003; LOERA, 2009). 
Esta vivência remete, em vários sentidos, para uma certa precariedade e incerteza (L'ESTOILE, 2014). Primeiro, pela falta de condições para investir em materiais de melhor qualidade e durabilidade. E depois para a precariedade de estatuto relativamente à propriedade da terra, por relação às casas de pedra, mais estáveis e seguras, que caracterizam tanto a casa-grande dos senhores-de-engenho como a própria casa de morada, onde habitavam os moradores com sítio, trabalhadores cuja condição relativamente privilegiada implicava uma relação prolongada de confiança com os proprietários. A segurança transmitida pelo proprietário aos trabalhadores através da relação de morada era vista por eles como uma das vantagens desta condição (PALMEIRA, 2009). Por outro lado, permite-nos ainda realçar a questão da temporalidade, acentuando o fato de que, num assentamento, a casa de taipa é uma construção nova, como são novas as pessoas que nela residem.

A diversidade de casas no assentamento compreende então casas de morada, casas de tijolo e casas de taipa. Estas diferentes tipologias de casa não estavam presentes em todas as parcelas, mas é frequente existir em cada parcela mais do que uma construção para fins de habitação. Neste caso, a existência de várias casas indica que, para além do casal titular, reside na mesma parcela um dos seus filhos casado. A segunda casa assinala uma nova geração posterior à da criação do assentamento. A sucessão geracional espelha-se assim, em Arupema, na frequência com que encontramos duas ou três casas por parcela, próximas umas das outras. Esta proximidade entre as primeiras habitações dos titulares e as dos seus filhos cria mais do que uma multiplicidade de residências. Cria uma nova unidade familiar: um agregado, uma "configuração de casas" ligadas por relações de parentesco (MARCELIN, 1999). Em torno do mesmo terreiro, estas duas casas estabelecem uma relação de complementaridade entre pais e filhos. É no conjunto das ações realizadas pelas várias pessoas da família que vivem nessas casas que se vai produzindo domesticidade (MARCELIN, 1999, p. 36), seja pela partilha da comida, o cuidado com as crianças ou o trabalho nas hortas e roçados. A casa dos pais deixa de ser apenas a casa da parcela (no modelo que compreende apenas uma parcela - uma casa - uma família nuclear), para ser a casa principal desta nova unidade de residência, que aglutina a família. Não se circunscrevendo ao edifício material, esta concepção abarca também outros espaços onde são realizadas atividades quotidianas social, económica e simbolicamente relevantes para a casa enquanto lugar da família. Neste sentido, podemos dizer que a casa é a parcela e que a parcela é o sítio.

Em princípio, o filho que ficar com a casa irá dispor também de terra para botar roçado, isto é, terra para trabalhar. Mesmo quando se trata de um filho solteiro, ao construir uma casa no terreiro da família, há um reconhecimento de que aquele filho já começou também a assumir a co-responsabilidade pela produção agrícola, através do seu trabalho. Assim, podemos considerar que a gestão da terra disponível na parcela entendida aqui enquanto área de cultivo ou terra de trabalho (GARCIA JR., 1983) - é um processo de parentesco que ocorre ao longo 
do tempo, uma vez que implica que um dos filhos permaneça na casa original da família ou construa nova casa no terreiro, assumindo assim a sua posição privilegiada na sucessão do poder da parcela e garantindo, idealmente, a sua posse no futuro.

Apenas em alguns casos a gestão do espaço na parcela permitia a construção de uma casa para que outros filhos que não o sucessor. Podendo também construir casa na parcela, estes outros filhos acabavam por investir menos o seu trabalho na atividade agrícola e na manutenção das roças e hortas, trabalhando frequentemente no corte da cana ou outro trabalho assalariado. Anteriormente, numa situação ideal enquanto moradores de engenho, cada família tinha direito a uma casa para morar e um pequeno sítio para plantar dentro da propriedade do patrão. Nessa casa, onde já haviam morado outros trabalhadores, residiam também os filhos que frequentemente ajudavam o pai no trabalho do engenho. Mas, quando algum deles pretendia casar e, por conseguinte, residir numa outra casa, não podia construir ali perto. Tinha de pedir ao senhor-de-engenho uma outra casa para morar e, assim, realizar com ele um contrato de trabalho, passando também ele a ser morador de engenho. A disponibilidade de lugar para a família dependia do número de trabalhadores do engenho, o que, por sua vez, dependia da vontade do senhor-de-engenho. Ouvi as expressões "me arrume esse sítio para eu morar" ou "me dê vinte dias de trabalho" na rememoração desses processos em que procurar uma casa de morada e "pedir trabalho" eram a mesma coisa. Assim, o chefe de família estabelecia uma dívida moral para com o proprietário (GARCIA JR., 2002). Os filhos dos moradores não podiam, portanto, instalar-se na proximidade dos pais e, apenas quando o morador morria seus filhos poderiam ficar na mesma casa, herdando a sua condição de morador. A situação era de tal forma rígida que os moradores não podiam sequer construir sem autorização do patrão, sob pena de expulsão (DABAT, 2007).

O mesmo problema se colocava entre os foreiros, cujas casas pertenciam igualmente ao proprietário. A destruição das casas dos foreiros por parte dos proprietários esteve na base do descontentamento e mobilização que deram origem às ligas camponesas na região nas décadas de 1950 e 1960 (FURTADO, 1964). Estes grupos organizados de foreiros, moradores e canavieiros insurgiram-se contra a expulsão das terras que ocupavam e onde produziam os seus próprios alimentos, um processo que ocorria em massa na época e que visava a incorporação de novas terras nos canaviais. Assim como as árvores de fruto, chamadas bens de raiz e reconhecidas no Estatuto da Terra de 1964, a existência de uma casa era considerada uma benfeitoria realizada por parte dos foreiros e, como tal, estes deveriam ser indemnizados pelos senhores-de-engenho aquando da sua saída da terra.

\section{Consideraçoes finais}

Como vimos, a preferência para a construção da casa na parcela aproxima-se da velha concepção de casa de morada e do próprio sítio do morador e correspondem às expectativas destes sem-terra locais que 
ocuparam os engenhos da região, acionando vários elementos simbólicos e históricos que, intersubjectivamente, estas pessoas partilham. Sobre esta utopia do engenho liberto enquanto combinação ideal entre o sítio e o engenho, veja-se o trabalho de SIGAUD (1977) e note-se que, por toda a Zona da Mata, os assentados da reforma agrária são justamente os antigos moradores de engenho e trabalhadores assalariados da cana que conviveram desde sempre com pequenos proprietários ou sitiantes localizados nos interstícios da plantation. Por sua vez, a construção das casas dos assentados revela também um processo através do qual são geridas - algumas vezes esbatidas e outras reproduzidas - as distinções e hierarquias sociais dentro de um assentamento que foi formado na justaposição de um antigo engenho de cana-de-açúcar.

A um nível estritamente formal, sucede então que, tal como acontecia com as regras da morada nos engenhos, que não previam que a transmissão da terra estivesse sob o controlo da família dos trabalhadores, num assentamento rural a transmissão da parcela também não pode ser controlada pelos descendentes do titular. Apenas neste sentido as restrições formais que suportam os assentamentos revelam a falta de lugar para a sucessão familiar. Apesar de a família ser a principal unidade social na acepção da reforma agrária brasileira, presente tanto na prática do MST como nos procedimentos do Incra, ela não comporta operativamente o prolongamento geracional que se realiza através da sucessão. É neste sentido que podemos caracterizar a reforma agrária como um modelo sincopado de assentamento de famílias.

Todavia, ao invés do que acontecia anteriormente, a liberdade de encontrar, na prática, soluções de trabalho ou habitação de iniciativa dos assentados é quase total, já que não se conhecem sanções nem necessidade de motins sociais para as conter. Esta perspectiva permite então reconsiderar a relação entre casa, morada e trabalho na longa tradição dos estudos rurais brasileiros, a partir dos novos desenvolvimentos resultantes da implementação da reforma agrária na região. $\mathrm{O}$ exercício possibilita ainda entender o modo como são atualizadas as noções de posse e uso da terra localmente. $\mathrm{O}$ fato de um casal fundador permanecer na parcela e nela criar condições para que os filhos residam e pelo menos um deles possa retirar o seu rendimento dela, viabiliza a permanência dos seus descendentes na terra. Instaura-se então um novo regime de valor da terra que se destaca do antigo modelo, onde a posse da terra passava necessariamente por depender do senhor-de-engenho e ainda do modelo sincopado que a reforma agrária estabelece. Neste sentido, a construção de novas casas nas parcelas materializou um sentido de apropriação futura da terra pelas novas gerações de filhos de assentados, recorrendo ao código partilhado da posse da terra através da presença continuada, onde morar e trabalhar são, finalmente, o que torna possível a construção do lugar da família e, assim, a própria família. 


\section{Resumen}

El modelo de reforma agraria puesto en marcha en Brasil en las últimas tres décadas supone una especie de contexto atemporal al basarse en una unidad operativa de familia nuclear que no considera la noción de extensión temporal ni de reproducción intergeneracional. Aunque la reproducción familiar sea una de las preocupaciones más características de las comunidades campesinas, la sucesión no fue prevista durante el proceso. Con el fin de entender cómo los asentados hicieran frente a esta situación, se presenta un análisis etnográfico de las casas de un asentamiento rural en la Zona da Mata de Pernambuco, donde se produjo un intenso debate respecto a los distintos modelos de organización espacial. Partiendo de la observación de la diversidad de categorías y materiales de las casas se propone una interpretación de su significado en conexión con la historicidad de las dinámicas familiares y los significados locales de la posesión de tierra.

Palabras clave: Familia. Reforma agraria. Zona da Mata de Pernambuco.

\section{Abstract}

The model of land reform implemented in Brazil in the last three decades rested on the assumption of a timeless framework by adopting as operational unit the nuclear family, with no temporal extension nor intergenerational reproduction. Despite family reproduction being one of the most characteristic concerns of peasant communities, succession was not something foreseen in the process. In order to understand the way the settlers dealt with the issue, this article presents an ethnographic analysis of the houses of a rural settlement at the Zona da Mata de Pernambuco where an intense debate between different models of spatial organization took place. Based upon the observation of the diversity of categories and materials of the houses we advance an interpretation of their meaning related to the historicity of family dynamics and local meanings of land ownership.

Keywords: Family. Land reform. Zona da Mata de Pernambuco

\section{Notas}

1 Este trabalho foi financiado por fundos nacionais através da FCT - Fundação para a Ciência e Tecnologia, I.P. (Portugal), no âmbito do projeto PTDC/CS-ANT7102957/2008 e de dois contratos de bolsa individual de doutoramento (SFRH/ BD/46957/2008 e SFRH/BD/61518/2009).

2 Como é comum nos trabalhos antropológicos, os nomes das pessoas e lugares referidos no texto foram substituídos. A escolha de pseudónimos procurou, contudo, não perder a sua verosimilhança.

3 MARA. Entrevista concedida à autora em novembro de 2010.

4 CELESTINO, Zé. Entrevista concedida à autora em novembro de 2010.

5 VÍTOR. Entrevista concedida à autora em novembro de 2010.

\section{Bibliografia}

CARSTEN, Janet. After Kinship. Cambridge: Cambridge University Press, 2004.

CORDEIRO, Manuela. Filhos da reforma agrária: terra, casa e lógicas de sucessão. 2010. Dissertação (Mestrado em Ciências Sociais em 
Desenvolvimento, Agricultura e Sociedade) - Programa de Pós-Graduação de Ciências Sociais em Desenvolvimento, Agricultura e Sociedade, Universidade Federal Rural do Rio de Janeiro, Rio de Janeiro, 2010.

. O recebimento do título definitivo em assentamentos: discursos acerca da propriedade da terra. In: CONGRESSO BRASILEIRO DE SOCIOLOGIA, 15, 2011, Curitiba. Anais... Curitiba: SBS, 2011. p. 1-20.

DABAT, Christine. Moradores de engenho: estudo sobre as relações de trabalho e condições de vida dos trabalhadores rurais na zona canavieira de Pernambuco, segundo a literatura, a academia e os próprios atores sociais. Recife: Editora Universitária da UFPE, 2007.

FREYRE, Gilberto. Casa grande $\mathcal{E}$ senzala. Lisboa: Livros do Brasil, 2001 (1933).

FURTADO, Celso. Dialética e desenvolvimento. Rio de Janeiro: Fundo de Cultura, 1964.

GARCIA JR., Afrânio. Terra de trabalho. Rio de Janeiro: Paz e Terra, 1983.

A sociologia rural no Brasil: entre escravos do passado e parceiros do futuro. In: CONGRESSO DA ASSOCIAÇÃO LATINO-AMERICANA DE SOCIOLOGIA RURAL, 2002, Porto Alegre. Anais... Porto Alegre: Universidade Federal do Rio Grande do Sul, 2002. p. 154-189.

HEREDIA, Beatriz Maria Alasia de. A morada da vida: trabalho familiar de pequenos produtores do Nordeste do Brasil. Rio de Janeiro: Paz e Terra, 1979.

L'ESTOILE, Benoît de. Money Is Good, but a Friend Is Better: Uncertainty, Orientation to the Future, and the Economy. Current Anthropology, Chicago, n. 55, v. S9, p. 62-73, 2014.

LEITE, Sérgio et al. (Org.). O impacto dos assentamentos: um estudo sobre o meio rural brasileiro. Brasília: Instituto Interamericano de Cooperação para a Agricultura; Núcleo de
Estudos Agrários e Desenvolvimento Rural; Unesp, 2004.

LOERA, Nashieli. Tempo de acampamento. 2009. Tese (Doutorado em Antropologia Social) PPGAS, Universidade Estadual de Campinas, Campinas, 2009.

MARCELIN, Louis Herns. A linguagem da casa entre os negros do Recôncavo baiano. Mana, Rio de Janeiro, v. 5, n. 2, p. 31-60, 1999.

MICAELO, Ana Luísa. Essa terra que tomo de conta: parentesco e territorialidade na Zona da Mata de Pernambuco. Lisboa: Imprensa de Ciências Sociais, 2016.

PALMEIRA, Moacir. Casa e trabalho: notas das relações sociais na plantation tradicional. In: WELCH, Clifford et al. (Org.). Camponeses brasileiros: leituras e interpretações clássicas. São Paulo: Editora da Unesp; MDA, NEAD, 2009 (1977). p. 203-215.

PINA-CABRAL, João de. Os contextos da antropologia. Lisboa: Difel, 1991.

SIGAUD, Lygia. A forma acampamento: notas a partir da versão pernambucana. Novos Estudos Cebrap, São Paulo, v. 58, p. 73-92, 2000.

A idealização do passado numa área de plantation. Contraponto, Porto Alegre, v. 2, p. 125-126, 1977.

SIGAUD, Lygia; ROSA, Marcelo; MACEDO, Marcelo. Ocupações de terra, acampamentos e demandas ao estado: uma análise em perspectiva comparada. Dados, Rio de Janeiro, v. 51, n. 1, p. 107-142, 2008.

VIEGAS, Susana de Matos. Terra calada: os Tupinambá na Mata Atlântica do sul da Bahia. Coimbra: Almedina, 2007.

WANDERLEY, Maria Nazareth. Morar e trabalhar: o ideal camponês dos assentados de Pitanga. In: MARTINS, José de Souza (Ed.). Travessias: a vivência da reforma agrária nos assentamentos. Porto Alegre: Editora Ufrgs, 2003. p. 203-246. 
WOLFORD, Wendy. Of land and labor: agrarian reform on the sugarcane plantations of Northeast Brazil. Latin American Perspectives, Riverside, v. 31, n. 2, p. 147-170, 2004.

WOORTMANN, Ellen. Herdeiros, parentes e compadres: colonos do sul e sitiantes do nordeste. São Paulo: Hucitec, 1995. 